\title{
Grid photocoagulation combined with intravitreal bevacizumab for recurrent macular edema associated with retinal vein occlusion
}

This article was published in the following Dove Press journal:

Clinical Ophthalmology

25 July $201 \mathrm{I}$

Number of times this article has been viewed

Ken Ogino

Akitaka Tsujikawa

Tomoaki Murakami

Yuki Muraoka

Yumiko Kurashige

Nagahisa Yoshimura

Department of Ophthalmology and Visual Sciences, Kyoto University Graduate School of Medicine, Kyoto, Japan
Correspondence: Akitaka Tsujikawa Department of Ophthalmology and Visual Sciences, Kyoto University Graduate School of Medicine, Sakyo-ku,

Kyoto 606-8507, Japan

Fax +81757520933

Email tujikawa@kuhp.kyoto-u.ac.jp
Purpose: To report the efficacy of grid photocoagulation combined with intravitreal bevacizumab (IVB) for macular edema recurring after previous IVBs associated with retinal vein occlusion (RVO).

Methods: This retrospective study consisted of 19 eyes with branch retinal vein occlusion (BRVO) and nine eyes with central retinal vein occlusion (CRVO), which were treated with grid photocoagulation combined with IVB for recurrent macular edema after previous IVBs. The mean duration of total follow-up was $29.3 \pm 5.8$ months.

Results: After this combination therapy, foveal thickness was reduced, significant with slight improvement in visual acuity (VA). At 1 month after treatment, although 25 of the 28 eyes showed complete resolution of the cystoid space, the macular edema recurred to some extent in 19 eyes. Compared with initial values, final foveal thickness was reduced significantly in both BRVO and CRVO groups $(P<0.001)$, but improvement in VA was significant only for eyes with BRVO $(P=0.012)$. The total number of IVB was $2.8 \pm 0.7$ for eyes with either BRVO or CRVO.

Conclusion: Grid photocoagulation combined with IVB has a substantial effect on reducing recurrent macular edema associated with RVO, but the effect on visual acuity is limited.

Keywords: bevacizumab, grid laser photocoagulation, macular edema, optical coherence tomography, retinal vein occlusion

\section{Introduction}

Macular edema remains one of the most common vision-threatening complications associated with retinal vascular disease such as retinal vein occlusion (RVO) or diabetic retinopathy, ${ }^{1-4}$ although various treatments have been reported to reduce this macular edema. ${ }^{5-11}$ Dysfunction of the endothelial blood-retinal barrier and increased vascular permeability may lead to leakage from the retinal capillaries, which results in macular edema. Today, vascular endothelial growth factor (VEGF) is known to play a major role in this increased vascular permeability. ${ }^{12}$ Because of the promising short-term effects of intravitreal bevacizumab (IVB), ${ }^{13}$ which is a recombinant human monoclonal antibody that binds to VEGF, anti-VEGF therapy is becoming a primary treatment for this condition. ${ }^{14}$ The effect of anti-VEGF agents is rapid, albeit short, ${ }^{15}$ and we often see a recurrence of the macular edema after complete resolution brought about by the IVB. Consequently, repeated IVB tends to usually be necessary. ${ }^{16}$

Grid photocoagulation is an evidence-based treatment of the macular edema associated with RVO. In a report by the Branch Vein Occlusion Study Group, ${ }^{10}$ grid photocoagulation to macular edema caused by branch retinal vein occlusion (BRVO) significantly improved long-term visual prognosis. In central retinal vein occlusion 
(CRVO), however, grid photocoagulation reduced the angiographic evidence of macular edema, but did not lead to improvement in the vision of treated eyes. ${ }^{1}$ Based on these reports, grid photocoagulation does have long-term effects on the reduction of macular edema due to RVO, but it is sometimes difficult to perform effective coagulation in eyes that have severe macular edema and retinal detachment due to acute RVO. The rapid effect of IVB in reducing the macular thickening may allow clinicians to perform grid photocoagulation more effectively and safely. In the study described herein, we report both the safety and efficacy of grid photocoagulation in combination with IVB for recurrent macular edema associated with RVO.

\section{Patients and methods}

For this retrospective study, we reviewed the medical records of 28 patients (28 eyes) who underwent grid photocoagulation combined with IVB for macular edema associated with RVO that recurred after the previous IVBs. In the present study, 19 patients (19 eyes) with BRVO and nine patients (nine eyes) with CRVO were examined at Kyoto University Hospital between December 2007 and November 2008. At the time of initial IVB (Avastin; Genentech, San Francisco, CA), all eyes showed macular edema with a loss of vision. Each patient underwent one or two injections of IVB for their macular edema. After the initial treatment with IVB, however, all eyes showed a recurrence. As treatment for the recurrent macular edema, each patient underwent an additional IVB first. Grid photocoagulation was performed immediately after the macular edema had been reduced by IVB.

Eyes with co-existing ocular disease (ie, epiretinal membrane, glaucoma, or proliferative diabetic retinopathy) were not recruited for this study. Pseudophakic eyes were included, but eyes that had undergone a prior vitrectomy were excluded. In the 28 eyes included in this study, previous treatment for macular edema before the initial IVB included three eyes that had been treated with grid laser photocoagulation, five eyes that had received intravitreal or posterior sub-Tenon injections of triamcinolone acetonide, and 1 eye that had received intravitreal injections of tissue plasminogen activator. All patients had at least a 12-month follow-up after the combination therapy; the mean duration of total follow-up time was $29.3 \pm 5.8$ months. This study was approved by the Institutional Ethics Committee and adhered to the tenets of the Declaration of Helsinki. Written informed consent was obtained from each patient.
Patients who had a visual disturbance due to macular edema associated with RVO were initially offered IVB treatment. At the time of initial IVB, foveal thickness was greater than $300 \mu \mathrm{m}$ and visual acuity (VA) was $\leq 0.7$ on a Landolt chart. Dosage of the bevacizumab was $1.25 \mathrm{mg} / 0.05 \mathrm{~mL}$ per injection, and all injections were performed in the usual sterile fashion; prophylactic topical antibiotics were applied for 1 week after the injection.

Initially, 22 eyes underwent one IVB injection, and six eyes underwent two IVB injections. All patients in the current study showed macular edema recurring after the initial IVBs. A recurrence of macular edema was defined as a relapse of the cystoid space at the foveal center and an increase of the foveal thickness to $>250 \mu \mathrm{m}$. For the recurrent macular edema, grid photocoagulation was performed immediately after the macular edema had been reduced by an additional IVB. Grid photocoagulation to the leaking area seen on the fluorescein angiogram was performed with a multicolor diode laser (MC-300; Nidek, Gamagori, Japan) with settings of $561 \mathrm{~nm}$ wavelength and $100 \mu \mathrm{m}$ spot size for 0.1 second; sufficient power (median $100 \mathrm{~mW}$, range 70-140 mW) was used to produce a burn detectable at the level of the retinal pigment epithelium. Each patient was scheduled to visit our clinic for an examination every month after treatment.

All patients had undergone a comprehensive ophthalmologic examination at each visit. This included best-corrected VA measurement, intraocular pressure determination, indirect ophthalmoscopy, slit-lamp biomicroscopy with a contact lens, and optical coherence tomography (OCT) examination. At the initial visit of each patient, fluorescein angiography was performed with a confocal laser scanning system (HRA-2; Heidelberg Engineering, Heidelberg, Germany); additional angiography was performed, if necessary. In the study described herein, macular area was examined precisely by OCT (Stratus OCT, Carl Zeiss, Dublin, CA; 3D-OCT1000, Topcon, Tokyo, Japan; Cirrus OCT, Carl Zeiss; RS3000; Nidek). Foveal thickness was calculated as the average retinal thickness within a circle having a 500- $\mu$ m radius; the circle was centered on the fovea.

Statistical analysis was performed using PASW statistics, (v 17.0; SPSS, Chicago, IL). All values are presented as mean \pm standard deviation. Best-corrected VA was measured with a Landolt chart and converted to a logarithm of the minimum angle of resolution (logMAR). VA and foveal thickness were compared with Tukey's HSD test after one factor repeated measurement of analysis of variance. A $P$ value of $<0.05$ was considered to be statistically significant. 


\section{Results}

Table 1 shows characteristics of the patients included in this study. Before initial IVBs, all eyes showed marked macular edema associated with RVO, often with a foveal cystoid space. Immediately after treatment, a reduction in clinical macular edema was seen and confirmed by OCT. Compared with preinjection measurements $(656.5 \pm 179.1 \mu \mathrm{m}$ in the BRVO group and $780.8 \pm 148.5 \mu \mathrm{m}$ in the CRVO group), foveal thickness was decreased significantly to $224.1 \pm 102.2 \mu \mathrm{m}$ in eyes with BRVO $(P<0.001)$ and to $245.9 \pm 101.2 \mu \mathrm{m}$ in eyes with $\mathrm{CRVO}(P<0.001)$ (Figure 1). In parallel with the reduction in macular edema, mean VA improved from $0.66 \pm 0.35$ to $0.37 \pm 0.30$ for eyes with BRVO $(P<0.001)$, and from $0.91 \pm 0.38$ to $0.69 \pm 0.26$ for eyes with CRVO $(P=0.067)$ (Figure 2$)$. All eyes in the current study, however, had a recurrence of macular edema with a visual disturbance.

Just before the combination therapy (termed "baseline"), all eyes showed cystoid spaces beneath the fovea, and the mean thickness of the fovea had increased to $518 \pm 112 \mu \mathrm{m}$ in the BRVO group and to $589 \pm 118 \mu \mathrm{m}$ in the CRVO group. The elapsed times from the previous IVB to the current combined therapy was $8.1 \pm 3.9$ months for eyes with BRVO and $4.4 \pm 1.5$ months for eyes with CRVO. The improvement in VA brought about by the previous IVBs had partially receded at the baseline visit; mean VA was now $0.53 \pm 0.34$ in the BRVO group and $0.81 \pm 0.29$ in the CRVO

Table I Background of the subjects

\begin{tabular}{|c|c|c|}
\hline & BRVO & CRVO \\
\hline Number of eyes & 19 & 9 \\
\hline Gender (male/female) & $5 / 14$ & $7 / 2$ \\
\hline Age (years) & $72.4 \pm 7.7$ & $74.1 \pm 8.2$ \\
\hline Hypertension & 6 & 7 \\
\hline Diabetes & 4 & I \\
\hline $\begin{array}{l}\text { Fluorescein angiography } \\
\text { (ischemic/nonischemic) }\end{array}$ & $11 / 8$ & $0 / 9$ \\
\hline \multicolumn{3}{|l|}{ Before initial IVB } \\
\hline Visual acuity (logMAR) & $0.66 \pm 0.35$ & $0.91 \pm 0.38$ \\
\hline Foveal thickness $(\mu \mathrm{m})$ & $656.5 \pm 179.1$ & $780.8 \pm 148.5$ \\
\hline Number of IVB (once/twice) & $13 / 6$ & $9 / 0$ \\
\hline \multicolumn{3}{|l|}{ Baseline } \\
\hline Visual acuity (logMAR) & $0.53 \pm 0.34$ & $0.81 \pm 0.29$ \\
\hline Foveal thickness $(\mu \mathrm{m})$ & $518.4 \pm 112.5$ & $588.6 \pm 118.4$ \\
\hline $\begin{array}{l}\text { Duration between initial IVB } \\
\text { and baseline (months) }\end{array}$ & $8.1 \pm 3.9$ & $4.4 \pm 1.5$ \\
\hline Follow-up (months) & $22.0 \pm 6.1$ & $23.3 \pm 4.8$ \\
\hline
\end{tabular}

Abbreviations: BRVO, branch retinal vein occlusion; CRVO, central retinal vein occlusion; IVB, intravitreal injection of bevacizumab; ischemic BRVO, showing $>5$ disc diameters of nonperfusion area; ischemic CRVO, showing $>10$ disc areas of nonperfusion; logMAR, logarithm of the minimum angle of resolution.

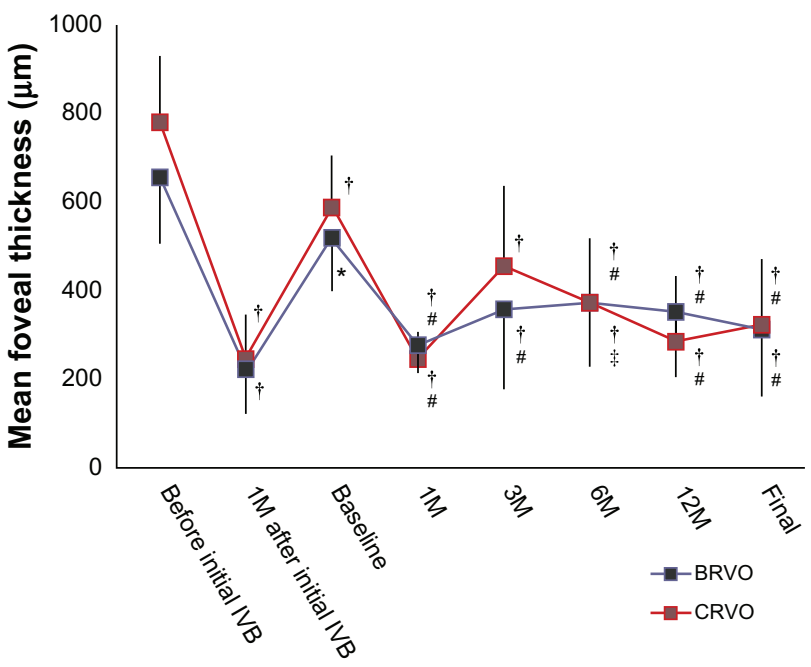

Figure I Mean foveal thickness in eyes that were treated with grid photocoagulation combined with an intravitreal bevacizumab (IVB) for the treatment of recurrent macular edema associated with retinal vein occlusion.

Notes: $* P<0.05$ and $t P<0.01$, compared with values before the initial treatment; $¥ P<0.05$ and $\# P<0.01$, compared with baseline values (just before grid photocoagulation combined with IVB).

Abbreviation: M, month(s).

group. On the combination therapy, each eye underwent an IVB first. Grid photocoagulation was performed after the macular edema had cleared, at $11 \pm 16$ days after IVB in eyes with BRVO and at $15 \pm 29$ days after IVB in eyes with CRVO. With this combination therapy, foveal thickness was reduced significantly to $276.7 \pm 90.9 \mu \mathrm{m}$ in eyes with BRVO $(P<0.001)$ and to $246.3 \pm 62.0 \mu \mathrm{m}$ in eyes with $\mathrm{CRVO}$

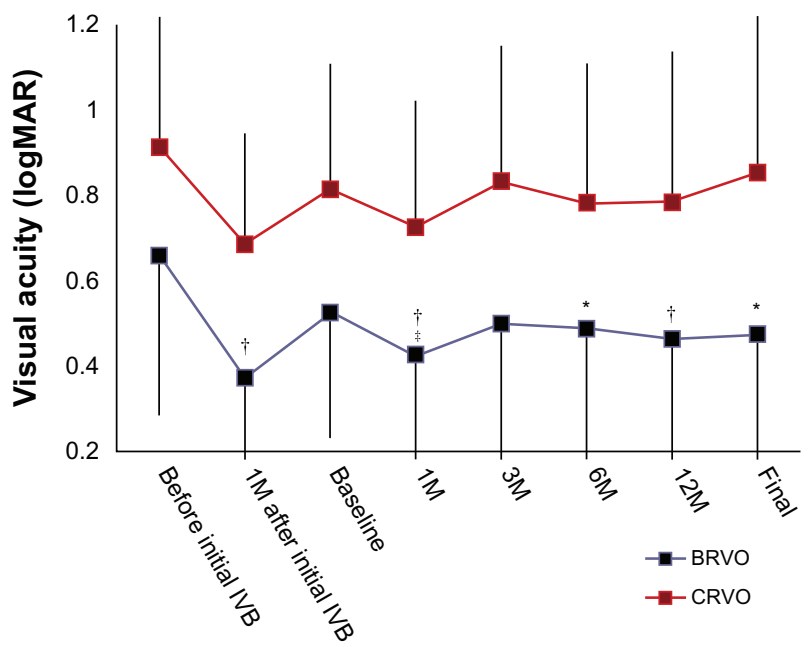

Figure 2 Visual acuity in logMAR of eyes treated with grid photocoagulation combined with an intravitreal bevacizumab (IVB) for the treatment of recurrent macular edema associated with retinal vein occlusion.

Notes: $* P<0.05$ and ${ }^{\dagger} P<0.0$ I, compared with values before the initial treatment; $\ddagger P<0.05$, compared with baseline values (just before grid photocoagulation combined with IVB).

Abbreviation: $M$, month(s). 
$(P<0.001)$ at 1 month after treatment, and VA improved slightly to $0.43 \pm 0.30$ in eyes with BRVO $(P=0.534)$, and to $0.72 \pm 0.30$ in eyes with $\mathrm{CRVO}(P=0.928)$. Also at 1 month after treatment, 17 of the 19 eyes with BRVO and eight of the nine eyes with CRVO showed complete resolution of the cystoid space (Figure 3). Thereafter, however, the cystoid space reappeared, to at least some extent, in twelve eyes with BRVO and in seven eyes with CRVO (Figure 4). Mean duration from the combination therapy to the recurrence was $3.3 \pm 1.2$ months in eyes with BRVO and $3.4 \pm 0.8$ months in eyes with CRVO. Ten eyes with BRVO and three eyes with CRVO needed additional IVB or grid photocoagulation, so the total number of IVBs was $2.8 \pm 0.7$ for both BRVO and CRVO.

Mean follow-up after this therapy was $22.0 \pm 6.1$ months in BRVO eyes and $23.3 \pm 4.8$ months in eyes with CRVO. At the final visit, macular edema had resolved completely and there was no cystoid space in 14 eyes with BRVO and in six eyes with CRVO. Figures 1 and 2 indicate the changes in foveal thickness and in VA with the series of treatments. At the final visit, foveal thickness was still significantly

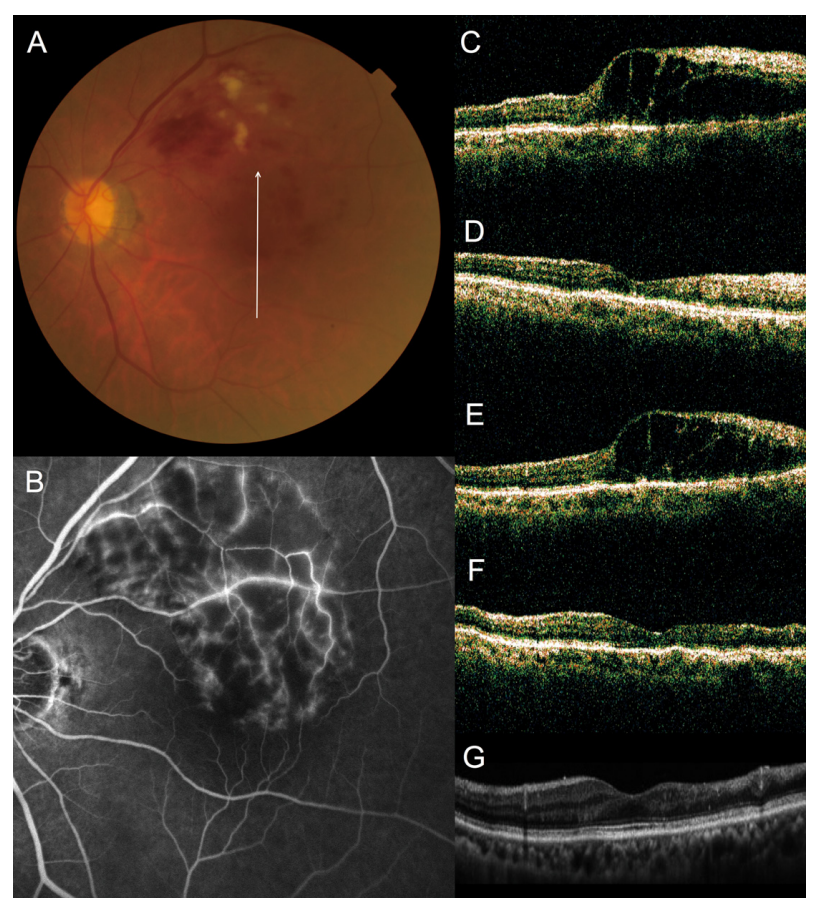

Figure 3 No recurrence of macular edema after grid photocoagulation combined with intravitreal bevacizumab (IVB) for recurrent macular edema associated with branch retinal vein occlusion. (A) An 83-year-old woman had a visual disturbance in the left eye $(0.3 \mathrm{OS})$ due to macular edema associated with branch retinal vein occlusion. (B) Fluorescein angiogram shows fluorescein leakage from the capillaries. (C-G), Vertical sectional images centered on the fovea with optical coherence tomography were obtained at the initial visit (C), at I month after the initial IVB (D), just before the combined therapy (at baseline, E), at I month after combined therapy $(\mathbf{F})$, and at the final visit $(\mathbf{G})$. She had no recurrence after the combination therapy $(0.8 \mathrm{OS})$.

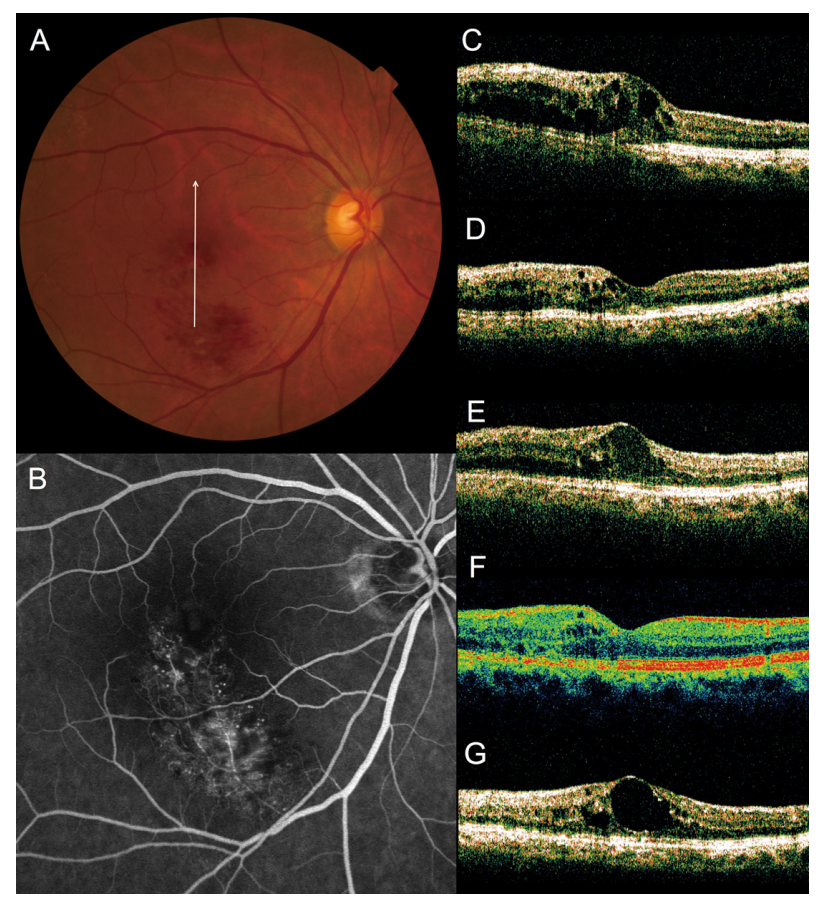

Figure 4 Recurrence of macular edema after grid photocoagulation combined with intravitreal bevacizumab (IVB) for recurrent macular edema associated with branch retinal vein occlusion. (A) A 65-year old woman had a visual disturbance in the right eye (0.6 OD) due to macular edema associated with branch retinal vein occlusion. (B) Fluorescein angiogram shows fluorescein leakage from the capillaries. (C-G), Vertical sectional images centered on the fovea with optical coherence tomography were obtained at the initial visit (C), at I month after initial IVB (D), just before the combined therapy (at baseline, E), at I month (F) and at 3 months (G) after the combined therapy. She had a recurrent cystoid space beneath the fovea after combination therapy (0.9 OD).

reduced compared with that at baseline in eyes with BRVO $(P<0.001)$ and in eyes with CRVO $(P<0.001)$. However, improvement in VA had receded at the final visit and returned to the baseline values $(0.47 \pm 0.34[P=0.974]$ in BRVO eyes, $0.85 \pm 0.50[P=0.999]$ in CRVO eyes). Comparing both VA and foveal thickness just before the initial IVB, final foveal thickness was reduced significantly in both BRVO eyes and CRVO eyes ( $P<0.001$, respectively), but the improvement in VA was significant only in those eyes with BRVO $(P=0.012)$.

\section{Discussion}

An increasing number of reports show the efficacy of antiVEGF therapy for macular edema secondary to RVO. Today, IVB is used to treat macular edema primarily in an off-label manner, as it was approved originally for the treatment of colon cancer. While the effect of IVB is rapid, it is usually necessary for repeated injections to maintain the initial effect. In a collaborative retina study, the mean number of $1.25 \mathrm{mg}$ IVB injections over a 24-month period was 7.2 for the treatment of macular edema associated with CRVO. ${ }^{17}$ Recently, 
however, large randomized clinical trials have revealed the 6-month results of monthly injections of ranibizumab for RVO. ${ }^{18,19}$ With monthly injections over 6 months, retinal thickening was continuously resolved and $>40 \%$ of eyes with CRVO and $>50 \%$ of eyes with BRVO gained 15 letters on VA testing, and a VA of $\geq 20 / 40$ was achieved in $40 \%$ of eyes with CRVO and in $60 \%$ of eyes with BRVO. Based on these reports, frequent injection of this anti-VEGF agent seems to be promising for macular edema due to RVO. Once the treatment has stopped, however, recurrence may occur. In addition, repeated intravitreal injections of any anti-VEGF agent increase the systemic and ocular adverse effects.

To reduce the number of injections, it would be effective (1) to distinguish those patients who do not require retreatment, ${ }^{20,21}$ (2) to design the optimum dosing and sequence, ${ }^{14,17,22,23}$ or (3) to switch to some other treatment if anti-VEGF therapy is not effective. In the current study, we aimed to reduce the number of IVB in eyes with recurrent macular edema by co-performing grid photocoagulation. Since the Branch Vein Occlusion Study Group recommended grid photocoagulation for macular edema associated with BRVO, for 25 years this has been seen as the primary treatment. The Central Vein Occlusion Study Group reported that grid photocoagulation reduced angiographic macular edema in eyes with CRVO. ${ }^{7}$ However, it may be difficult to perform effective coagulation when macular edema and retinal detachment are severe. In such cases, it is often necessary to increase the laser power in order to ensure sufficient coagulation, and it may be necessary to frequently change the laser intensity depending on the extent of retinal thickening and hemorrhage. By combining IVB with photocoagulation, we were able to produce burns with a relatively low setting of the laser $(100 \mathrm{~mW}$ in intensity, 0.1 millisecond in duration, $100 \mu \mathrm{m}$ in spot size). This protocol allowed us to perform grid photocoagulation more safely; ${ }^{24}$ so far, no adverse effects have been detected in these patients, except for the recurrence of the macular edema.

In this study, the combination therapy was performed to macular edema recurred after the effective previous IVB. This combination treatment reduced foveal thickness as effectively as did the previous IVB. However, improvement in VA was not as effective as was the previous IVB. Cystoid edema had resolved completely in $89 \%$ of eyes at 1 month, but $63 \%-78 \%$ of eyes ultimately showed a recurrence. At the final visit, although foveal thickness was significantly reduced compared with baseline values, improvement in VA had receded and had returned to baseline values. Compared with measurements just before the initial IVB, final foveal thickness was reduced significantly in both the BRVO and CRVO groups, but the improvement in VA was significant only in eyes with BRVO. Based on the current findings, grid photocoagulation has the substantial effect of reducing the macular edema associated with RVO, but its efficacy for visual recovery appears to be limited.

Limitations of the current study are the retrospective nature and small sample size. Our study lacked control arms: patients who were continued on IVB alone when their macular edema recurred, and those who received continuous monthly IVB throughout the study period. In addition, this study consisted of only those patients with recurrent macular edema, so that it is difficult to compare our current results with those of other reports. Based on the current results, however, the effect of this combination therapy on visual recovery is limited. Because the total number of injections of IVB was $2.8 \pm 0.7$ for both the BRVO and CRVO groups during a mean total follow-up period of $29.3 \pm 5.8$ months, the number of IVB injections is low. In addition, grid photocoagulation in our study was performed quite safely and with low laser intensity. Based on the current results, we suggest that grid photocoagulation combined with IVB be used for recurrent macular edema associated with RVO - at least when it is difficult to perform repeated IVB.

\section{Disclosure}

The authors declare no conflicts of interest.

\section{References}

1. Frank RN. Diabetic retinopathy. N Engl J Med. 2004;350(1):48-58.

2. Wong TY, Scott IU. Clinical practice. Retinal-vein occlusion. $N$ Engl $J$ Med. 2010;363(22):2135-2144.

3. Retinopathy and nephropathy in patients with type 1 diabetes four years after a trial of intensive therapy. The Diabetes Control and Complications Trial/Epidemiology of Diabetes Interventions and Complications Research Group. N Engl J Med. 2000;342(6):381-389.

4. Giuliari G. Images in clinical medicine. Intravitreal triamcinolone for diabetic macular edema. $N$ Engl J Med. 2010;363(24):2351.

5. Greenberg PB, Martidis A, Rogers AH, Duker JS, Reichel E. Intravitreal triamcinolone acetonide for macular oedema due to central retinal vein occlusion. Br J Ophthalmol. 2002;86(2):247-248.

6. Lahey JM, Fong DS, Kearney J. Intravitreal tissue plasminogen activator for acute central retinal vein occlusion. Ophthalmic Surg Lasers. 1999; 30(6):427-434.

7. Evaluation of grid pattern photocoagulation for macular edema in central vein occlusion. The Central Vein Occlusion Study Group M report. Ophthalmology. 1995;102(10):1425-1433.

8. Opremcak EM, Bruce RA, Lomeo MD, Ridenour CD, Letson AD, Rehmar AJ. Radial optic neurotomy for central retinal vein occlusion: a retrospective pilot study of 11 consecutive cases. Retina. 2001;21(5): 408-415.

9. Jonas JB, Kreissig I, Degenring RF. Intravitreal triamcinolone acetonide as treatment of macular edema in central retinal vein occlusion. Graefes Arch Clin Exp Ophthalmol. 2002;240(9):782-783. 
10. Argon laser photocoagulation for macular edema in branch vein occlusion. The Branch Vein Occlusion Study Group. Am J Ophthalmol. 1984;98(3):271-282.

11. Photocoagulation for diabetic macular edema. Early Treatment Diabetic Retinopathy Study report number 1. Early Treatment Diabetic Retinopathy Study research group. Arch Ophthalmol. 1985;103(12): 1796-1806.

12. Aiello LP, Avery RL, Arrigg PG, et al. Vascular endothelial growth factor in ocular fluid of patients with diabetic retinopathy and other retinal disorders. $N$ Engl J Med. 1994;331(22):1480-1487.

13. Rosenfeld PJ, Fung AE, Puliafito CA. Optical coherence tomography findings after an intravitreal injection of bevacizumab (avastin) for macular edema from central retinal vein occlusion. Ophthalmic Surg Lasers Imaging. 2005;36(4):336-339.

14. Campochiaro PA, Hafiz G, Channa R, et al. Antagonism of vascular endothelial growth factor for macular edema caused by retinal vein occlusions: two-year outcomes. Ophthalmology. 2010;117(12): 2387-2394.

15. Krohne TU, Eter N, Holz FG, Meyer CH. Intraocular pharmacokinetics of bevacizumab after a single intravitreal injection in humans. $\mathrm{Am} \mathrm{J}$ Ophthalmol. 2008;146(4):508-512.

16. Matsumoto Y, Freund KB, Peiretti E, Cooney MJ, Ferrara DC, Yannuzzi LA. Rebound macular edema following bevacizumab (Avastin) therapy for retinal venous occlusive disease. Retina. 2007; 27(4):426-431.

17. Wu L, Arevalo JF, Berrocal MH, et al. Comparison of two doses of intravitreal bevacizumab as primary treatment for macular edema secondary to central retinal vein occlusion: results of the pan American collaborative retina study group at 24 months. Retina. 2010;30(7): 1002-1011.
18. Brown DM, Campochiaro PA, Singh RP, et al. Ranibizumab for macular edema following central retinal vein occlusion: six-month primary end point results of a phase III study. Ophthalmology. 2010;117(6): 1124-1133.

19. Campochiaro PA, Heier JS, Feiner L, et al. Ranibizumab for macular edema following branch retinal vein occlusion: six-month primary end point results of a phase III study. Ophthalmology. 2010;117(6): 1102-1112.

20. Hoeh AE, Ruppenstein M, Ach T, Dithmar S. OCT patterns of macular edema and response to bevacizumab therapy in retinal vein occlusion. Graefes Arch Clin Exp Ophthalmol. 2010;248(11):1567-1572.

21. Ach T, Hoeh AE, Schaal KB, Scheuerle AF, Dithmar S. Predictive factors for changes in macular edema in intravitreal bevacizumab therapy of retinal vein occlusion. Graefes Arch Clin Exp Ophthalmol. 2010;248(2):155-159.

22. Wu L, Arevalo JF, Berrocal MH, et al. Comparison of two doses of intravitreal bevacizumab as primary treatment for macular edema secondary to branch retinal vein occlusions: results of the Pan American Collaborative Retina Study Group at 24 months. Retina. 2009;29(10): 1396-1403.

23. Shroff D, Bhargava A, Sharma B, Gupta C, Shroff C. Combined treatment of intravitreal bevacizumab and intravitreal triamcinolone in patients with retinal vein occlusion. Graefes Arch Clin Exp Ophthalmol. 2010;248(8):1203.

24. Parodi MB, Iacono P, Ravalico G. Intravitreal triamcinolone acetonide combined with subthreshold grid laser treatment for macular oedema in branch retinal vein occlusion: a pilot study. Br J Ophthalmol. 2008; 92(8):1046-1050.
Clinical Ophthalmology

\section{Publish your work in this journal}

Clinical Ophthalmology is an international, peer-reviewed journal covering all subspecialties within ophthalmology. Key topics include: Optometry; Visual science; Pharmacology and drug therapy in eye diseases; Basic Sciences; Primary and Secondary eye care; Patient Safety and Quality of Care Improvements. This journal is indexed on

\section{Dovepress}

PubMed Central and CAS, and is the official journal of The Society of Clinical Ophthalmology (SCO). The manuscript management system is completely online and includes a very quick and fair peer-review system, which is all easy to use. Visit http://www.dovepress.com/ testimonials.php to read real quotes from published authors. 